out in the more conducive environment of NHS facilities.

We have serious doubts regarding the viability of the scrutiny team's proposals; in particular we believe that the purchasers (the prison service) will not be able to find adequate providers (NHS doctors). A corps of part time doctors devoted to the service already exists, but experience tells us that few others are likely to last the course.

DAVID COOPER

Newport,
Isle of Wight

East Farleigh,

Kent ME15 0JT

PETER DENING-SMITHERMAN

Hayling Island,

DAVID DOHERTY

Hampshire

Middleton on Sea

West Sussex

Cirencester,

WILLIAM OLDHAM

Gloucestershire GL7 IWD

WILLIAM STEPHEN

Haywards Heath,

Sussex RH16 2NB

DUDLEIGH TOPP

Haywards Heath,

Sussex RH17 7NQ

Bristol BS9 4BT

PETER TRAFFORD

1 Smith R. Arise the new prison health service. $B M \mathcal{F} 1990 ; 301$ : 892. (20 October.)

\section{Screening for carriers of cystic fibrosis}

SIR, - Further to the case report by Dr Felix $\mathbf{H}$ Sennhauser and colleagues ${ }^{1}$ we have screened 15 partners of people heterozygous for cystic fibrosis from Aberdeen. We found one couple in which the partner also carried a cystic fibrosis mutation ( $\triangle \mathrm{F} 508)$

Prenatal diagnosis was not undertaken for this couple because the mutation in the known carrier (the mother, who had had an affected child by her previous partner) could not be identified and because gestation was too far advanced at presentation. The mother's cystic fibrosis-bearing chromosome was subsequently identified by using a linked marker ( $\mathrm{pJ} 3.11$ ), permitting future prenatal diagnosis. In six other couples we originally screened the partner for only $\Delta \mathrm{F} 508$, and in the other eight nine mutations were excluded.

The residual risk of having an affected child despite a negative test result in the partner with no family history should be calculated by using Bayes's theorem, and not by the simple method used by $\mathrm{Dr}$ Sennhauser and colleagues. They calculated the risk that the man is a carrier and that the woman is $\Delta 508$ negative, given that she is a carrier (the joint probability), whereas we wish to know the risk that the woman is a carrier, given that she is $\Delta \mathrm{F} 508$ negative (the posterior probability).

The Bayes's risk (with Sennhauser and colleagues' notation $)$ is $1 / 4 \times((1-a) \times q) /((1-a) \times q)+p)$ or 1 in 257 -a small but important increase over their result ( 1 in 267). It should also be noted that the probability of $\triangle F 508$ not occurring in an unrelated partner is $1-\mathrm{aq}$, or $96.5 \%$, and not $98.4 \%$ as stated by Sennhauser and colleagues.

The mutation $\Delta F 508$ accounts for $73 \%$ of cystic fibrosis mutations in Scotland, and a further $16 \%$ are accounted for by the less common mutations G551D，G542X，R117H，R553X，1717G $\rightarrow$ A, $\mathrm{R} 560 \mathrm{~T}, 621+1 \mathrm{G} \rightarrow \mathrm{T}$, and $\Delta \mathrm{I} 507$. For couples screened only for $\triangle F 508$ the residual risk calculated with a population carrier frequency of 1 in 25 is 1 in 360 . If all the above mutations are excluded then the risk falls to 1 in 877 , an extremely low value.

Couples at increased risk commonly request screening when they know that it is available although pregnancy is often the stimulus to presentation. If the obligate carrier does not carry an identifiable mutation (expected in about $11 \%$ of cases) a family study with linked markers is required. This takes much longer to organise than direct mutation screening of the presenting couple. There is a need for increased awareness among the public (and medical profession) of the possibilities and limitations of cystic fibrosis genetic testing.

JOHN C S DEAN

Aberdeen Royal Infirmary, KEVIN F KELLY

Aberdeen AB9 IGS

University of Aberdeen Aberdeen AB9 2ZD

ZOSIA MIEDZYBRODZKA

Human Genetics Unit,

Edinburgh EH4 2XU

1 Sennhauser FH, Liechti-Gallati S, Moser H. Screening fo carriers of cystic fibrosis among partners of people heterozygous for the disease. BMf 1990;301:1081. (10 November.)

\section{Choosing a partner in general practice}

SIR,-As the attributes reported by Drs Jennifer King and Michael Whitfield as important for selecting and appointing a partner in general practice seem to be the views of two people, ${ }^{1}$ we believe that it is relevant to report the results of our postal survey of 89 general practitioner principals (including 20 trainers) and 21 general practitioner trainees on the importance of postgraduate qualifications, postregistration job experience, and personal circumstances when choosing a potentia partner.

We received 101 replies, an overall response rate of $92 \%$. The order of importance (rated as essential, highly desirable, desirable, irrelevant, undesirable) of postgraduate qualifications was MRCGP DRCOG (about seven people thought each was essential; 34 thought MRCGP essential or highly desirable, 43 thought DRCOG essential or highly desirable) followed by the DCH and DGM. Increasing irrelevance was expressed for the MRCP, FRCS, DA, and intercalated BSc or other degree. Authorship of scientific papers and holding academic prizes were similarly thought irrelevant. Even the MRCGP and DRCOG were thought irrelevant by 20 and 10 respondents respectively. Among postregistration job experiences obstetrics and gynaecology was seen as essential or highly desirable by 84 , paediatrics by 72 , care of the elderly by 64 , general medicin by 64 , casualty by 53 , and psychiatry by 47 . Dermatology; ear, nose, and throat surgery; general surgery; ophthalmology; and anaesthetic were thought less useful $(32,31,27,23$, and three responding essential or highly desirable, respectively)

Eighty one respondents had no preference on sex, and 57 had no age preference (above or below 30 years), although 33 considered marital attachment as essential or highly desirable compared with 22 who thought it irrelevant. Single, divorced, or cohabiting candidates were generally thought undesirable. Half preferred candidates who had never deviated from a path towards general practice, although only two thought that having worked outside was positively undesirable. A medically oriented or qualified spouse was considered desirable or essential by 39 and thought irrelevant by 61 . Forty approved of extended travel abroad or having worked abroad.

We suggest that applicants for general practice should have postgraduate experience in obstetrics, paediatrics, care of the elderly, general medicine, casualty, and psychiatry. They should hold the MRCGP, DRCOG, DCH, and DGM, be married, and have a career oriented towards general practice.

S G BARBER K STAVELEY A DOWN

North Devon District Hospital

Devon EX31 4JB

1 King $\mathrm{J}$, whitfield $M$. How to choose a new partner in general practice. $B M \mathcal{F}$ 1990;301:1258-60. (1 December.)

\section{Early diagnosis of acute myocardial infarction}

SIR,-Dr Adam Timmis and several correspondents discussed ways of diagnosing myocardia infarction early. ${ }^{12}$

Acute inflammatory stimuli, including ischaemia, produce an increase in systemic vascular permeability that seems to be amplified in the kidney by the renal concentrating mechanism and leads to low level proteinuria. ${ }^{3-5}$ In patients with acute intermittent claudication, ischaemia induced by exercise results in increased urinary albumin excretion within 60 minutes, which is proportiona to the severity of claudication as judged by the fall in ankle blood pressure.

To study the effects of myocardial infarction on urinary protein excretion we collected urine within two to 24 hours (mean 10.9 hours) after the onset of symptoms in 96 patients admitted to two coronary care units with suspected myocardial infarction. The diagnosis was confirmed in 44 patients based on electrocardiography and changes in serum enzyme activities; the remaining 52 patients served as a control group. Myocardial infarction was diagnosed if urinary albumin concentration was above $1.5 \mathrm{mg} / \mathrm{mmol}$ creatinine and IgG concentration above $0.9 \mathrm{mg} / \mathrm{mmol}$ creatinine. If one or both tests gave values below these cut off points myocardial infarction was excluded. Measuring albumin and IgG concentrations in the first urine passed after admission gave a diagnostic sensitivity of $80 \%$ with specificity of $96 \%$ and a predictive value for myocardial infarction of $96 \%$.

In the search for early markers for acute myocardial infarction it may be worth studying the increase in renal permeability to plasma proteins, which seems to be a rapid and proportional response to acute ischaemic episodes.

PETER GOSLING

Selly Oak Hospital,

Birmingham B29 6JD

University Hospital of Wales,

TIMOTHY M REYNOLDS

Cardiff CF4 4XW

1 Timmis A. Early diagnosis of acute myocardial infarction. $B M \mathcal{J}$ 1990;301:941-2. (27 October.)

2 Correspondence. Early diagnosis of acute myocardial infarction. BMF 1990;301:1213-4. (24 November.)

3 Gosling P, Sutcliffe AJ, Cooper MACS, Jones AF. Burn and trauma associated proteinuria: the role of lipid peroxidation, renin and myoglobin. Ann Clin Biochem 1988;25:530-59.

4 Gosling P, Shearman CP, Gwynn BR, Simms MH, Bainbridg ET. Microproteinuria: response to operation. BMF 1988;296: ET. Mict

5 Shearman CP, Gosling P, Gwynn BR, Simms MH. Systemi effects associated with intermittent claudication. A model to study the biochemical aspects of vascular disease. Eur $\mathcal{F}$ Vasc Surg 1988;2:401-4.

6 Hickey NC, Gosling P, Baar S, Shearman CP, Simms MH. Effect of surgery on the systemic inflammatory response to intermittent claudication. Br F Surg 1990;77:1121-4.

7 Gosling P, Hughes EA, Reynolds TM, Fox JP. Microalbuminuria is an early response following acute myocardial infarction. Eur Heart $\mathcal{f}$ (in press)

SIR, - We write with reference to Dr Adam D Timmis's editorial' and the letter from Dr P J Mullen. ${ }^{2}$

We, too, have conducted a study using time 